\title{
Coping with COVID-19
}

\author{
Social distancing in response to COVID-19 need not mean social or scientific isolation. Adaption to technology now \\ could lead to more innovative, sustainable and inclusive communication in the future.
}

O n 23 January 2020, as preparations for the Lunar New Year got underway, some 60 million people were quarantined in Hubei province, China. Across the region, celebrations were cancelled and public life was suspended as the population self-isolated to slow the spread of SARS-CoV-2, the virus responsible for COVID-19. Growth of new cases in China may have decreased but the novel Coronavirus is now established around the world ${ }^{1}$; a situation that changes rapidly and is impossible to capture in print. The global response has included travel restrictions; school and university closures; and social distancing. As the world comes to grips with the pandemic, our informal survey of geoscience academics in China reveals the indirect toll COVID-19 is taking on scientific collaborations and suggests geoscientists need to embrace new ways of communicating to keep science flowing.

In China, geoscientists have faced huge changes in how they work. For some senior researchers we talked to, reduced travel and administrative duties have allowed more time to focus on papers that were previously a low priority. At the same time, slow Internet connections; limited access to literature; home distractions; poor desk spaces; anxiety; and caring responsibilities have frustrated and limited the work of others. In the short term, any advantages of working from home appear to have favoured those with a backlog of data more often senior academics.

That said, these senior scientists are not complacent about the longer-term impacts of this health crisis on geoscience research: no one knows how fieldwork may be affected; many have sensitive equipment in laboratories without maintenance access; and all have students and junior colleagues to worry about. The early-career researchers we contacted emphasized that university closures and conference cancellations would limit their ability to generate data and build collaborative networks. The personal experiences of some geoscientists in China reflect a wider concern that restricted interaction between scientists and reduced travel negatively impact academic careers ${ }^{2}$, and scientific progress.

Geoscience research relies on collaborations - often across institutional and international boundaries. Conferences

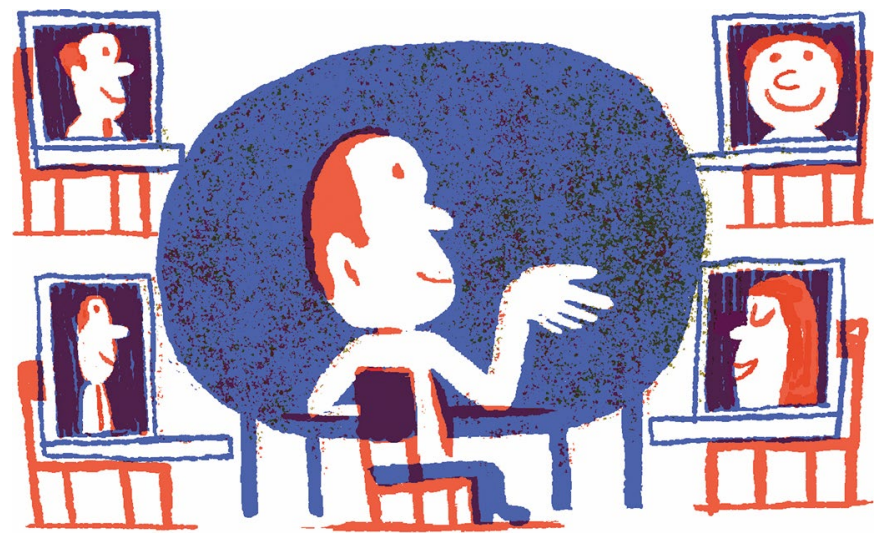

Credit: Nick Shepherd / Alamy Stock Photo

offer a boundary-crossing opportunity and the widespread disappointment at their cancellation emphasizes the high value placed on them by the community. Conferences are mixing pots. They combine a scheduled program with opportunities for informal conversations, from which new ideas and collaborations emerge. While there have been tweaks to the conference format over the years - such as flash talks or the part-poster, part-oral PICO presentations - most are still predicated on in-person attendance. Past attempts at virtual meetings ${ }^{3,4}$ have not yet come close to overturning the traditional conference format.

In the short term, it is unlikely that cancelled conferences can adapt quickly enough to be as effective virtually. The technology to host more than a simple meeting is lacking but the enthusiasm to share science is clearly not. While it may be too soon to imagine a geoscience mega-conference such as the AGU Fall Meeting hosted via video or in virtual reality, academics in China have found hosting administrative meetings online so convenient that they plan to continue after the COVID-19 crisis ends. With the EGU General Assembly moving to EGU2020: Sharing Geoscience Online, COVID-19 could be the impetus to test the communication tools that already exist, and to develop the technology that does not. In the future, virtual meetings may nurture collaboration in the same way that in-person meetings can.
Future conferences need not move entirely online. There could be compromises such as multi-hub conferences, in which people gather in Internet-connected regional centres. This conference style can reduce conference associated greenhouse gas emissions by up to $50 \%{ }^{5}$ and allow scientists with limited time, funds or ability to travel to attend a meeting they would otherwise miss. It is possible that what the community may lose in terms of in-person contact it would gain from the inclusion of those previously left out.

The full impact of COVID-19 has yet to been seen but it has pushed many to try new technology - or apply old technology in new ways. While everyone we spoke with in China has a unique experience, they unanimously agreed that nothing can totally replace face-to-face contact. Nonetheless, digital communication has maintained the collaborative spirit of the geosciences. Physical isolation may be necessary to limit the spread of COVID-19, but there is an opportunity to get technologically creative with communication, and to reach out across boundaries in innovative ways, now, and in the future.

Published online: 2 April 2020 https://doi.org/10.1038/s41561-020-0569-2

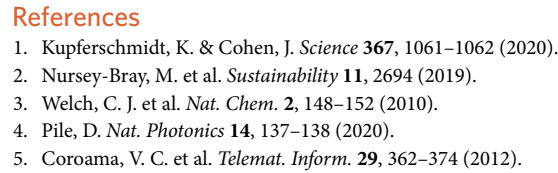

